\title{
Controversies on the endoscopic and surgical management of pain in patients with chronic pancreatitis: pros and cons!
}

\author{
Asbjørn Mohr Drewes, ${ }_{1} 1$ Marinus A Kempeneers, ${ }^{2}$ Dana K Andersen, ${ }^{3}$ \\ Lars Arendt-Nielsen, ${ }^{4}$ Marc G Besselink, ${ }^{2}$ Marja A Boermeester, ${ }^{2}$ \\ Stefan Bouwense, ${ }^{5}$ Marco Bruno, ${ }^{6}$ Martin Freeman, ${ }^{7}$ Thomas M Gress, ${ }^{8}$ \\ Jeanin E van Hooft, ${ }^{9}$ Bart Morlion, ${ }^{10}$ Søren Schou Olesen, ${ }^{\oplus 1}$ \\ Hjalmar van Santvoort, ${ }^{11,12}$ Vikesh Singh, ${ }^{13}$ John Windsor ${ }^{14}$
}

\section{INTRODUCTION}

Pain is the dominating symptom of chronic pancreatitis (CP) causing impairment of quality of life, decreased activity, unemployment and major healthcare costs. ${ }^{1}$ Opinions differ on the best strategy to treat CP-related pain. These differences are fuelled by the lack of a clear correlation between the severity of complaints

${ }^{1}$ Centre for Pancreatic Diseases, Department of Gastroenterology, Aalborg University Hospital \& Clinical Institute, Aalborg University, Aalborg, Denmark

${ }^{2}$ Department of Surgery, Amsterdam Gastroenterology and Metabolism, Amsterdam UMC, University of Amsterdam, Amsterdam, The Netherlands

${ }^{3}$ Division of Digestive Diseases and Nutrition, National Institute of Diabetes and Digestive and Kidney Diseases, National Institutes of Health, Bethesda, Maryland, USA ${ }^{4}$ Center for Sensory-Motor Interactions (SMI), Faculty of Medicine, Aalborg University, Aalborg, Denmark ${ }^{5}$ Department of Surgery, Radboud University Medical Center, Nijmegen, The Netherlands

${ }^{6}$ Department of Gastroenterology and Hepatology, Erasmus MC, University Medical Center, Rotterdam, The Netherlands

${ }^{7}$ Division of Gastroenterology, Hepatology and Nutrition, University of Minnessota Medical School, Minneapolis, Minnesota, USA

${ }^{8}$ Department of Gastroenterology, Philipps University \& University Hospital of Marburg, Marburg, Germany ${ }^{9}$ Department of Gastroenterology and Hepatology, Amsterdam Gastroenterology and Metabolism,

Amsterdam UMC, University of Amsterdam, Amsterdam, The Netherlands

${ }^{10}$ The Leuven Centre for Algology \& Pain Management, University Hospitals Leuven, Leuven, Belgium

${ }^{11}$ Department of Surgery, St Antonius Hospital,

Nieuwegein, The Netherlands

${ }^{12}$ Department of Surgery, University Medical Center

Utrecht, Utrecht, The Netherlands

${ }^{13}$ Division of Gastroenterology, Johns Hopkins Medical Institutions, Baltimore, Maryland, USA

${ }^{14}$ Surgical and Translational Research Centre, Faculty of Medical and Health Sciences, University of Auckland,

Auckland, New Zealand

Correspondence to Professor Asbjørn Mohr Drewes, Gastroenterology, Aalborg University Hospital, Aalborg 9000, Denmark; amd@rn.dk and Professor Marc G Besselink, Department of Surgery, Amsterdam Gastroenterology and Metabolism, Amsterdam UMC, University of Amsterdam, The Netherlands;

m.g.besselink@amc.uva.nl and the presence and extent of morphological abnormalities, lack of a comprehensive pain assessment tools, deficiency in the knowledge about the natural course of CP and the presence of (changes in) both peripheral and central nervous system pain mechanisms.

Analgesics are the cornerstone of pancreatic pain management, but when opioids are used, it may lead to dependency and opioid-induced hyperalgesia. ${ }^{2}$ When analgesic therapy fails, invasive treatments including endoscopic pancreatic duct clearance (with or without extracorporeal shock wave lithotripsy (ESWL)) or pancreatic duct stenting and surgery (resection and/or ductal decompression) are used. The rationale for invasive treatments is that reducing ductal pressure by restoring pancreatic juice flow and/or resecting an inflammatory pancreatic mass will result in pain relief. However, there is also a neuropathic basis for pain in most patients, for which invasive treatments may not be effective or even harmful. While there are many clinical studies that support invasive treatments, there is a paucity of high-quality randomised controlled trials (RCTs). As a result, the current guidelines for endoscopic and surgical treatments for painful CP are inconsistent and tend to reflect a specialty bias. ${ }^{3}$ For example, the German guidelines ${ }^{4}$ recommend surgery as the most effective treatment of pain, whereas the European Society of Gastrointestinal Endoscopy ${ }^{5}$ and the international evidence-based (HaPanEU) guidelines ${ }^{1}$ advice a 'step-up approach' incorporating both conservative, endoscopic and surgical treatment. These contradictions allow historic bias and a significant variation in clinical practice. Gut received a review article on the treatment of pain in CP that challenged current guideline recommendations and initiated a lively and exciting debate between authors and reviewers, which the editors of Gut wanted to share with their readers. For this purpose, a novel article format was designed, which would allow both sides ('pros' and 'cons') to present and discuss their views on the clinical and experimental studies that provide the evidence for invasive treatment of pain in patients with CP, to identify the knowledge gaps and to define what is required for the conduct of future studies, and to debate the pros and cons. To address these aims, this article is authored by opinion leaders in favour (MAK, SAWB, JEvH, HCvS, DKA, MLF, JAW, MJB, MAB, MGB) and against (AMD, SSO, BM, LA-N, VKS) the current interventional treatment recommendations and moderated by the associate editor of Gut for pancreatic diseases (TMG).

\section{THE CONS OF INTERVENTIONAL TREATMENT OF PAIN IN CHRONIC PANCREATITIS}

Pathophysiology of pain contradicts the rationale for invasive treatment

For many years, the theoretical framework for the invasive treatment of patients with painful CP has been that the pain is generated by localised pathology, namely focal pancreatic duct obstruction and/or localised inflammatory mass. This framework is challenged by the inability to demonstrate any relationship between pancreatic morphology and pain ${ }^{67}$ or postoperative pain relief. ${ }^{8-10}$ This lack of correlation between morphology and pain is not unique to CP, but is also evident in patients with endometriosis, osteoarthritis, neuropathic pain and peptic ulcer. ${ }^{11}$ Therefore, invasive treatments (surgery or endoscopy) directed to overcome partial or complete pancreatic duct obstruction (the 'plumbing theory' in figure 1), including endoscopic stenting, endoscopic stone removal and decompressive pancreato-jejunostomy, ${ }^{12-14}$ may not be justified for many patients. Further, a substantial proportion of patients with typical pancreatic pain do not have major morphological changes (eg, 'minimal change' and 'small duct' CP) that are amenable to surgical or endoscopic treatment.

Neuroablative procedures including endoscopic celiac plexus blockade, surgical splanchnicectomy and even total pancreatectomy target neuropathic pain (the 'wiring theory' in figure 1), but suffer from the same fundamental problems as the aforementioned decompression procedures. It is known that neuropathy, as defined by the International Association for the Study of Pain, plays a major 


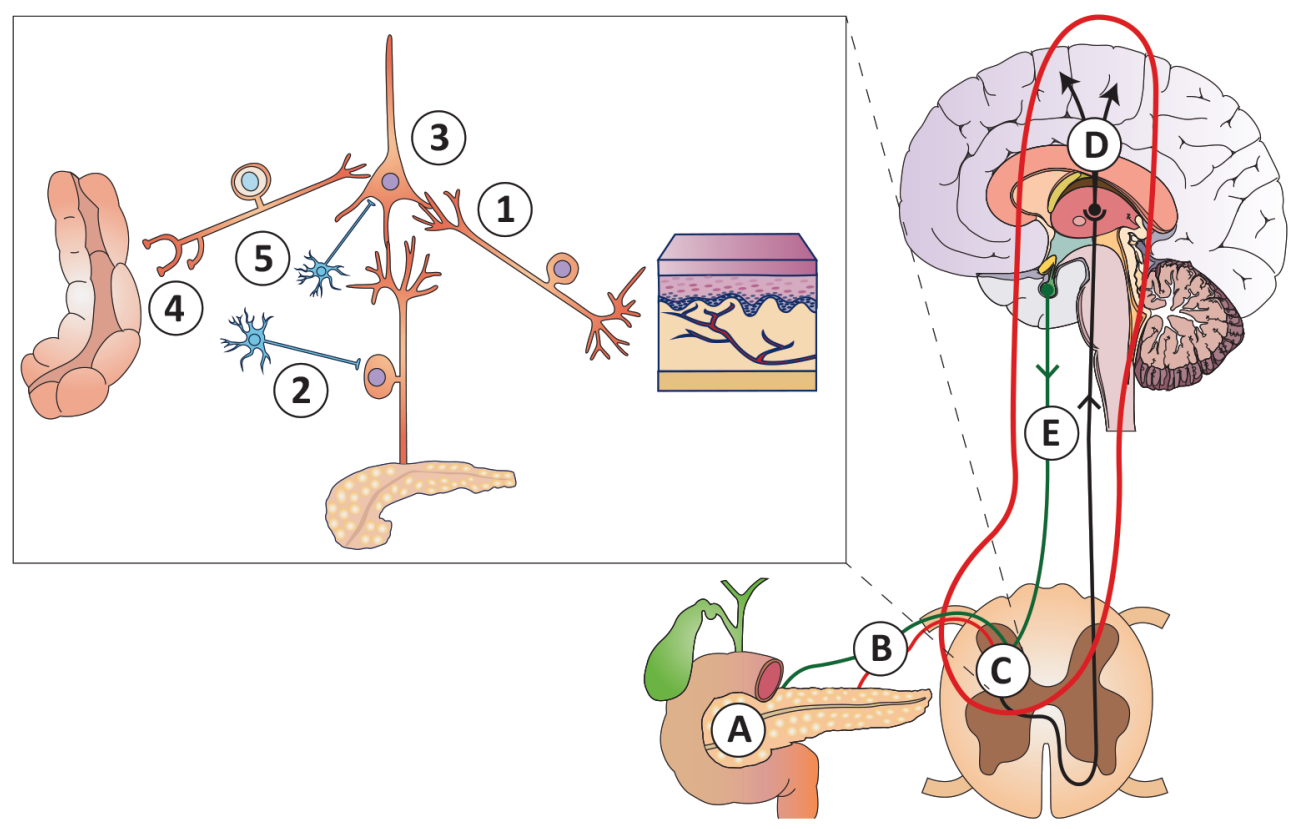

Figure 1 Schematic overview of the pathophysiology of pain in chronic pancreatitis, for details see Olesen et al. ${ }^{19}(A)$ Mechanical obstruction of the pancreatic duct system and/or increased intra-glandular pressure (the 'plumbing' theory), as well as local inflammatory masses. (B) Peripheral nerve damage with ectopic activity resulting in stimulus-dependent and spontaneous pain (the 'wiring' theory). (C) (insert): (1) Sprouting of non-nociceptive nerve afferents normally responsible for non-painful sensations into 'pain-specific' areas of the spinal cord resulting in allodynia (pain to stimuli that are normally not painful); (2) sprouting of sympathetic neurons into the dorsal horn neurons rendering the system sensitive to sympathetic activity and catecholamine; (3) sensitisation and phenotypic changes of spinal neurons due to increased afferent barrage; (4) abnormal coding of the afferent input from other viscera (and somatic structures) resulting in increased referred pain and viscero-visceral hyperalgesia; (5) local disinhibition by interneurons that normally controls pain intensity. (D) Reorganisation and structural changes in the brain that encodes complex sensations such as affective, evaluative and cognitive responses to pain. (E) Defects in descending pathways arising in the brain stem that normally inhibit the peripheral afferent activity at the spinal cord level.

role in painful $\mathrm{CP},{ }^{15}$ and the severity of neuropathy is correlated with pain intensity. ${ }^{16}$ Neuropathic changes have been discovered at all levels of the nervous system (figure 1). ${ }^{17-19}$ Sensitisation of central nociceptive pathways is accelerated by acute disease flares and painful comorbid conditions. ${ }^{18}$ Hence, continued nociceptive input on central pathways may ultimately result in an autonomous and self-perpetuating pain state, which is independent of the peripheral nociceptive drive. ${ }^{11}$ When this state develops, it is unlikely that any local neuroablative procedure will be effective. ${ }^{19}$ In support, generalised hyperalgesia in patients with painful CP, as objectively measured with quantitative sensory testing (QST), was associated with failure of thoracoscopic splanchnic denervation. ${ }^{20}$

The argument for invasive treatments of neuropathic pain is that removal of the source of nociceptive pain (eg, by pancreatic resection) would decrease the barrage from primary afferents and, over time this would reduce pain severity. Similarly, the argument for neuroablative procedures is that this would decrease primary afferent activity and therefore pain severity. This has some credence as neural blocks and local analgesics can be effective for peripheral nerve injury and painful polyneuropathy. ${ }^{21-24}$ However, while medical treatment aims to reduce the membrane potentials and firing thresholds of pathological neural circuits, there is evidence that neuroablative procedures (after initial alleviation of pain) can promote spontaneous firing of peripheral afferents due to disinhibition and upregulation of ion channels. This can lead to a cascade of central nervous system events followed by sensitisation and worsening of pain. ${ }^{25}$ Hence, procedures based on neural destruction may promote development of new neuropathic pain, formerly known as 'deafferentation pain'. ${ }^{18}$ Taken together, these mechanisms may explain the reduced long-term efficacy of invasive treatments. $^{26}$

\section{What can surgeons learn from invasive treatments in other painful conditions?}

For lack of other options, surgeons have historically attempted to excise chronic pain. Although not studied after pancreas surgery, consequences after nerve damage are dependent on procedure rather than disease, and therefore, the experience from invasive treatment in other diseases is valid in this context. Destructive, irreversible neurolytic procedures have included cauterisation of the sciatic nerve for sciatica, amputations for limb pain, dorsal root entry zone rhizotomies and resection of neuromas for phantom limb pain. ${ }^{27}$ Such approaches have failed and the lack of controlled clinical data has meant that these techniques have become historical anecdotes. ${ }^{28}$ Despite this, the continuing support for pancreatic resection for chronic pain persists in the treatment of CP and has been given further impetus with popularisation of total pancreatectomy with islet auto transplantation (TPIAT), including resection even before the onset of pain.

Some surgical treatments for chronic pain can be considered neuroablative. A common example is microdiscectomy for the management of radicular pain. Although many patients with sciatica report pain relief in the first 3 months, most still had mild to moderate symptoms 5 years after surgery. ${ }^{29}$ Another 
example of this is revisional surgery after total knee arthroplasty, where $85 \%$ of revision patients have more intense pain and sensitisation compared with their baseline levels. ${ }^{3031}$ More recently, neuromodulation has been developed as a less invasive treatment option, including spinal cord stimulation and targeted intrathecal pharmacotherapy (eg, morphine pump). ${ }^{32}$ While these are considered relatively safe and produce significant pain reduction, there is a lack of randomised placebo-controlled trials to support it. ${ }^{33} 34$

\section{Flaws in studies of invasive treatments for painful chronic pancreatitis}

Treatment by endoscopy and/or surgery are commonly offered as part of a step-up approach, when lifestyle changes and drug treatment fails. ${ }^{25}$ Many observational studies or studies comparing different procedures have reported benefits from endoscopic and surgical treatment of CP pain. ${ }^{36}$ However, these symptomatic benefits are time dependent, and it is common for relapse to occur over time. ${ }^{2637-39}$ This relapse may be due to progression of the neuropathy, development of further duct strictures and/or fibroinflammatory processes, as well as the loss of the placebo effect of intervention. ${ }^{40}$

Studies related to neuroablative procedures are often biased by patient selection, have failed to control for differing aetiologies and definitions of CP, have a short follow-up period, and/or use poor pain assessment methodology. ${ }^{40}$ For example, celiac plexus neurolysis improves analgesia and decreases opioid consumption in patients with pancreas cancer, ${ }^{32}$ but benefits are time limited (about 3 months). As the nerve damage may even worsen the neuropathic mechanisms as outlined above, it should be considered obsolete in patients with painful CP. ${ }^{2} 4142$ TPIAT involves denervation and is becoming increasingly available. Although open studies have shown that both total pancreatectomy (alone) and TPIAT can reduce pain, there are significant issues with risk, cost and consequences of such an invasive treatment. Some of the benefits may derive from better monitoring and control of diabetes and greater attention to nutritional management. Additionally, a critical follow-up study has showed that most TPIAT patients develop functional pain and other pain syndromes, ${ }^{43}$ and caution is advised to promote this treatment outside protocolled studies.

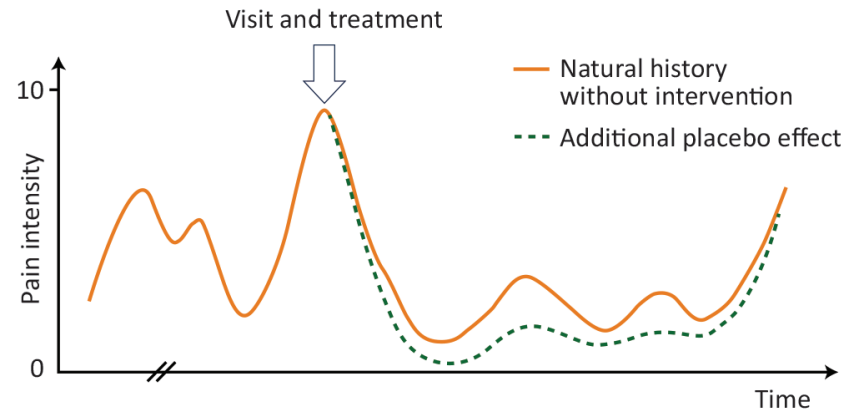

Figure 2 A hypothetical illustration of the pain intensity over time (solid curve) in a patient with chronic pancreatitis. At the initial course of disease, the pain is fluctuating and may reach a high intensity as illustrated on the y-axis. When pain intensity is the highest, the patient may be desperate and seek invasive treatment (arrow). However, the natural course of disease (in this case, the pain temporarily improves) is not taken into consideration when the outcome of uncontrolled studies of invasive treatment is evaluated. Such a selection bias necessitates a control group subjected to sham surgery/endoscopy before any definitive conclusions regarding effectiveness of treatment can be taken. The placebo effect (stippled green line) can further add to the pain relief after invasive treatments.

\section{Sham-controlled studies are mandatory to confirm the effect of invasive treatments}

The well-known placebo effect has also been investigated in pharmacological pain management of CP. The effect size is about $20 \%,{ }^{44}$ and this is similar to what has been found in studies with analgesics for other conditions, including painful gastrointestinal diseases. ${ }^{45}$ As no placebo/ sham-controlled trials of invasive therapies for painful CP exist, previous studies may be subject to selection bias and the effects on pain per se are still unanswered (figure 2). Due to lack of studies in CP, it is worthwhile to consider the effect of sham-controlled surgical trials for other painful conditions. Examples include laparoscopic adhesiolysis for abdominal pain, arthroscopic meniscectomy for knee pain, subacromial decompression for shoulder pain, percutaneous coronary intervention for angina and vertebroplasty for painful vertebral compression fractures. ${ }^{47-53}$ Although these procedures are well established and the indication for pain has not been questioned (with results similar to surgery for CP (table 1)), all the studies demonstrated no difference in pain intensity between active treatment and sham. This was confirmed in meta-analyses of invasive procedures for painful conditions (other than CP), where improvements in the sham arm was seen in up to $75 \% .^{54-56}$ Another more recent meta-analysis confirmed that the effect of sham surgery on pain was about 40\%, with studies reporting up to $60 \%$ pain improvement. ${ }^{56}$ More specifically for pancreatology, Cotton et al randomised 214 patients with sphincter of Oddi dysfunction to sphincterotomy or sham. ${ }^{57}$ There was reduction in pain in both groups, but the sham treatment performed significantly better. Later, the authors reported that the $47 \%$ of the sham-treated patients had $>50 \%$ reduction in pain and $37 \%$ had no pain at all. ${ }^{58}$ This study has questioned the use of invasive treatments in patients with pancreatogenic pain. It is worth noting that the effect size of sham treatment in these studies is of a similar magnitude to that seen in studies investigating endoscopic and surgical treatment for painful CP (table 1). Unfortunately, the ethical challenges of conducting sham-controlled studies in surgery (open or laparoscopic) in CP are well recognised, ${ }^{59}$ but in contrast, it is possible to conduct sham-controlled endoscopic treatments. ${ }^{3}$

\section{THE PROS OF INTERVENTIONAL TREATMENT OF PAIN IN CHRONIC PANCREATITIS}

In the recent international evidence-based (HaPanEU) guidelines, a multidisciplinary step-up approach for the treatment of pain in CP was recommended, ${ }^{1}$ although specific trials investigating this approach are yet to be performed. The first step is conservative therapy, including lifestyle management (eg, cessation of alcohol use and smoking), dietary advice and pain medication. The approach to pain management of the WHO is widely accepted for pain treatment in CP, although it has not been formally evaluated. ${ }^{60}$ If patients have persistent pain despite appropriate conservative measures, including optimisation of pain medication, subsequent interventional endoscopy or surgery is 
Table 1 Highlights of studies on pain treatment in chronic pancreatitis

\begin{tabular}{|c|c|c|c|c|c|}
\hline Study & Design & $\mathrm{N}$ & Interventions & Follow-up & Pain relief $(\%)^{*}$ \\
\hline \multicolumn{6}{|l|}{ Endoscopy } \\
\hline Rosch et $a l^{12}$ & Cohort & 1018 & Endoscopy (including ESWL) & 4.9 years $\dagger$ & 65 \\
\hline Tadenuma et $a l^{11}$ & Cohort & 57 & Endoscopy (including ESWL) & 1 year & 63 \\
\hline Dumonceau et $a l^{72}$ & $\mathrm{RCT}$ & 55 & ESWL with/without subsequent endoscopy & 2 years & 55 vs $62(p=0.651)$ \\
\hline \multicolumn{6}{|l|}{ Conventional surgery } \\
\hline Dite et $a^{/ 11}$ & RCT & 72 & Endoscopy (without ESWL) versus surgery & 5 years & 61 vs $86(p=0.002)$ \\
\hline Cahen et $a l^{13}$ & RCT & 39 & Endoscopy (including ESWL) versus surgery & 2 years & 32 vs $75(p=0.007)$ \\
\hline Cahen et $\mathrm{al}^{26}$ & Long-term results $\mathrm{RCT}$ & 31 & Endoscopy (including ESWL) versus surgery & $>6$ years & 38 vs $80(p=0.042)$ \\
\hline \multicolumn{6}{|l|}{ TPIAT } \\
\hline Bellin et $a^{82}$ & Cohort & 215 & TPIAT & 10 years & 82 \\
\hline \multicolumn{6}{|c|}{ Neuropathic pain medication } \\
\hline Olesen et $\mathrm{al}^{67}$ & RCT & 64 & Pregabalin versus placebo & 3 weeks & 36 vs $24(p=0.02)$ \\
\hline
\end{tabular}

${ }^{*}$ Complete and partial pain relief combined.

†Mean.

CP, chronic pancreatitis; ESWL, extracorporeal shockwave lithotripsy; RCT, randomised controlled trial; TPIAT, total pancreatectomy with islet autotransplantation.

recommended. While endoscopy is often used as the first approach in patients with solitary strictures and single pancreatic duct stones in the head of the pancreas, there are also indications for surgery as the first intervention, such as an inflammatory head mass in which cancer cannot be excluded. There is a large literature, both non-randomised and randomised, supporting the efficacy of interventional endoscopy and surgery in the treatment of symptomatic CP. ${ }^{132661}$

\section{Interventions in chronic pancreatitis: what we know}

Medical therapy

Around 50\% of patients with CP require pain medication on a daily basis, and the vast majority take opioids, despite the lack of evidence that they are effective for longterm pain management. ${ }^{62} 63$ Further, the longer patients are treated with opioids, the greater is the risk of opioid dependence and side effects such as opioid-induced constipation, cognitive dysfunction and hyperalgesia. ${ }^{16465}$ As a result, there is acceptance that the lowest effective dose of opioids should be used.

Patients with long-standing CP can develop changes in the central nervous system leading to pain that is less dependent on peripheral driving factors (nociception from local inflammation of the pancreas). ${ }^{66}$ To treat this 'central sensitisation' and reduce the effective opioid dose, neuropathic pain medication (eg, gabapentin or amitriptyline) is widely used in clinical practice in conjunction with other analgesics and interventional treatment in CP. Only one trial investigated this strategy in the short term (see table 1), and long-term efficacy is unknown. ${ }^{67}$ What is important to note, especially in the absence of compelling evidence, is that all analgesic strategies are adjunctive because they do not specifically target the drivers of painful CP.

All patients requiring opioid analgesia for CP should be discussed at a multidisciplinary meeting to determine whether they should be referred for interventional endoscopy or surgery. ${ }^{1}$ A large proportion of these patients will have morphological abnormalities such as a ductal obstruction with upstream dilatation due to ductal strictures, ductal stones, inflammatory pancreatic (head) mass and/or pseudocysts. $^{12} 68 \quad 69$ Although the correlation between pain and the presence and extent of morphological abnormalities is highly variable, several RCTs have confirmed pain relief attributable to the interventions in the majority of these patients, see table $1 .^{12}$

\section{Interventional endoscopy}

There are a number of morphological abnormalities that can be treated by interventional endoscopy on the premise that the intervention reduces pancreatic duct obstruction and hypertension. These interventions include pancreatic and biliary stricture dilation/stenting, pancreatic duct stone removal and drainage of pseudocysts. $^{70}$ Several observational cohort studies have reported a long-term pain relief in substantial proportions of patients following interventional endoscopy. Two studies of 57 and 1018 patients reported pain relief in $>60 \%$ of the patients after 1 and 5 years, respectively. ${ }^{1271}$ In patients with large intraductal stones $(>5 \mathrm{~mm})$, ESWL and subsequent endoscopic stone extraction can be effective. ${ }^{170}$ There is one RCT in which ESWL with and without subsequent endoscopic stone extraction was compared in 55 patients. After 2 years, the pain relief was comparable between both groups (55\% vs $62 \%) .{ }^{72}$ See table 1 for a structured overview of studies mentioned above.

\section{Surgery}

Surgery is effective both in patients with a ductal obstruction and an inflammatory head mass. The most commonly performed procedure is pancreatic duct drainage by a lateral pancreaticojejunostomy, in which the pancreatic duct is opened along its entire length and anastomosed (side to side) to a Roux-Y jejunal limb. ${ }^{73}$ An inflammatory head mass can be resected using pancreatoduodenectomy or a duodenum preserving pancreatic head resection such as the Berne, or Beger procedures. ${ }^{74}$ Ductal drainage and duodenum preserving (partial) head resection are combined in a Frey procedure. ${ }^{76}$ Surgery is reported to have a good longterm effect although approximately 10\% of patients will not respond, and this risk is higher in patients who have had a large number of endoscopic procedures prior to surgery. ${ }^{77}$

Two RCTs have compared endoscopic and surgical management in patients with painful obstructive CP. ${ }^{13}{ }^{61}$ Both studies showed superiority of surgical over endoscopic management. The study of Dite et al randomised 72 patients with $\mathrm{CP}$ and reported, after 5 years of follow-up, $34 \%$ complete and 52\% with partial relief after surgery, versus $15 \%$ had complete pain absence and $46 \%$ partial relief after endoscopy. However, endoscopy in this study was not optimal since no ESWL was applied. ${ }^{61}$ The study by Cahen et al randomised 39 patients with painful obstructive CP and reported, after 2 years 
of follow-up, $75 \%$ pain relief after surgery versus $32 \%$ after endoscopy, which included ESWL $(p=0.007) .{ }^{13}$ In longterm follow-up, these results remained stable after $>6$ years, with $80 \%$ pain relief in the surgery group versus 38\% pain in the endoscopy group. ${ }^{26}$ Complete pain relief was seen in 53\% of patients after surgery versus $25 \%$ after endoscopy. ${ }^{26}$ It was also noted that $47 \%(9 / 16)$ of the endoscopic-treated patients required delayed surgery, and complete pain relief was found in only 2/9 (22\%) patients with delayed surgery compared with the $8 / 15$ (53\%) who had primary surgery. Several RCTs that compared different surgical strategies for CP have reported long-term pain relief of around $80 \%$ after $7-15$ years follow-up..$^{3978} 79$ The most recent international RCT compared duodenum-preserving pancreatic head resection with pancreatoduodenectomy in 250 patients with CP and an inflammatory pancreatic head mass. Two years after surgery, pain scores and the mean quality of life significantly improved in both groups, without significant differences. ${ }^{80}$

An evolution in the surgical intervention for CP is TPIAT, first reported in 1977. As conventional surgery and endoscopic treatment may not be feasible or successful in up to $50 \%$ of patients, TPIAT is based on the concept of complete removal of the source of pain while maintaining islet cell function to avoid or mitigate the risk of diabetes by infusing the patient's own islet cells into the portal circulation to engraft within the liver. ${ }^{81}$ Application of TPIAT is growing worldwide and it might be considered appropriate for paediatric patients, those without pre-existing diabetes, those with hereditary pancreatitis and those with small duct disease for whom decompression is not possible. A single-centre observational study has reported on 215/742 TPIAT patients with at least a 10-year follow-up. Complete and sustained pain relief was present in $82 \%$ at 10 years and $90 \%$ at 15 years, with either full or partial islet graft function in nearly $50 \%$ patients. $^{82}$

Based on the available evidence, both surgery and endoscopy are durable (and not time dependent as suggested by the con group), although surgery provides the superior outcome (table 1). There are some patients who will benefit from an endoscopy-first approach, including those with (single) pancreatic duct stones or strictures confined to the head of the pancreas in whom complete ductal clearance can be achieved. While this is a reasonable approach, there is a risk of delay in referral for surgery when the outcome of endoscopy proves unsatisfactory. An increasing body of evidence suggests that earlier surgical intervention leads to better pain control. ${ }^{83-85}$ After the onset of pain, a (long) delay before invasive treatment increases the risk of opioid dependence and may lead to sensitisation of central pain pathways and changes in pain perception, which increases the chance of treatment failure. ${ }^{86}$ On this basis, the CON group actually favour earlier intervention in painful, obstructive CP.

\section{Interventions in chronic pancreatitis: what we do not know \\ Timing of intervention}

In current clinical guidelines, there is inconsistency regarding the timing and whether endoscopy or surgery should be offered as the first intervention for patients with painful obstructive CP. ${ }^{1270}$ There is increasing evidence that suggests that earlier surgery leads to better pain relief rather than the unproven step-up approach, in which medication and then endoscopy are offered first. ${ }^{83-85}$ It is known that delay in intervention, prolonged and repeated episodes of pain and opioid dependency are associated with the development of neuropathic pain. ${ }^{64}$ To resolve this longstanding debate about the timing of intervention, the Dutch Pancreatitis Study Group conducted the ESCAPE trial. ${ }^{88}$ Patients with painful obstructive CP and a dilated pancreatic duct in a very early phase of treatment, with a maximum of 2 months of opioid use and no prior interventions, were eligible. These patients were randomised to either surgical treatment within 6 weeks or an optimised current step-up approach including endoscopic treatment. Primary outcome was pain as assessed by the Izbicki pain score, a validated pain score specific for CP and widely used. ${ }^{13} 899^{90}$ The preliminary results of the ESCAPE trial were presented at United European Gastroenterology Week 2018 but final results are still awaited.

Sham-controlled trials: good in theory, problematic in practice

Although all endoscopic and surgical intervention trials in CP have shown pain relief in a clinically relevant proportion of patients, none of them used sham interventions. Trials with a sham intervention as comparator can estimate the placebo effect of an intervention, something of particular interest with studies of pain treatment. There is indeed evidence that the placebo effect can account for up to $65 \%$ of the treatment effect for invasive procedures, especially when treating pain. ${ }^{55}$ Sham-controlled studies, however, are subject to debate for both ethical and practical reasons. ${ }^{91}$ A sham intervention might be considered as dishonest in clinical practice, whereas it is a legitimate aspect of research design. ${ }^{92}$ There is an inherent difficulty in incorporating a blinded sham-control arm in surgical procedures, although this can be done more easily in endoscopic studies. ${ }^{54}$ It is also difficult for clinicians to deny treatment that they consider effective and when not convinced that equipoise exists, even in the context of an RCT, such as trial requires long-term follow-up, and many would consider it unethical to deny potentially effective treatment for years. Lastly, the effect size of endoscopic and surgical treatment is such that it seems highly improbable that this could be accounted for by a sham intervention alone. Is it ethical to withhold patients from other treatment options for such a prolonged period, even if these other options have been shown to be successful without sham comparison?

\section{FACTORS THAT INFLUENCE THE OUTCOME FROM INVASIVE} TREATMENT: RECOMMENDATIONS FOR FUTURE TRIALS

Advances in the treatment of patients with painful CP will require an improved study design that takes into account the many risk factors that influence outcome (table 2). Studies have shown that demographic variables and imaging features are important in the outcomes from surgery. ${ }^{8} 10859394$ Alcohol and smoking also influences outcomes, and alcohol abstinence can improve the effect of surgery. ${ }^{9}$ Compared with hereditary or idiopathic CP, patients with toxic aetiologies have improved outcomes from resectional or decompressive procedures, ${ }^{10}$ but worse after TPIAT. ${ }^{939596}$ This implies that the aetiology of CP is a more important factor than any morphological changes of the pancreas, and future trials should more carefully consider the effect of smoking and drinking continuance/cessation. Other factors including depression, widespread pain, expectations, catastrophizing and sleep deprivation may also be important although less well studied in $\mathrm{CP}^{297}$ Age also influences outcome with a greater efficacy from TPIAT in children as discussed below. 
Table 2 Factors to be considered in the design of future trials of the endoscopic and surgical treatment of pain in chronic pancreatitis

\begin{tabular}{|c|c|}
\hline Factors & Comments \\
\hline Demography & Variables including age, sex and recurrent acute pancreatitis may influence outcome \\
\hline Aetiology & Toxic aetiology (alcohol and smoking) predicts a better outcome on pain after surgical resection, although the opposite was found after TPIAT \\
\hline Imaging features & $\begin{array}{l}\text { Parenchymal calcifications have predicted postoperative pain relief in some studies. Patients with strictures and stones in the main pancreatic duct may } \\
\text { respond to invasive therapies, but as pathology of the pancreatic duct system is not associated with clinical pain, responders need to be identified }\end{array}$ \\
\hline Procedures & Multiple endoscopic procedures may negatively affect outcome \\
\hline Opioid use & $\begin{array}{l}\text { Opioid use has a negative effect on outcome, but represents a bias as the patients typically represent a subgroup with more severe pain, disability and } \\
\text { reduced quality of life that predicts a bad outcome to treatment per se }\end{array}$ \\
\hline Pain evolution & $\begin{array}{l}\text { Long pain duration may affect the outcome in a negative way, but data are subject to selection and recall bias. A temporal association between the } \\
\text { development of pancreatic morphological changes and pain may predict a favourable prognosis to invasive treatments }\end{array}$ \\
\hline Pain descriptors & $\begin{array}{l}\text { Intermittent pain pattern, as opposed to constant pain, may be associated with better outcomes and probably reflects the absence of central } \\
\text { sensitisation }\end{array}$ \\
\hline Pain assessment & $\begin{array}{l}\text { Validated tools for assessment of the multidimensional pain experience, including assessment of physical, psychological and social functioning, are } \\
\text { recommended. Catastrophizing and psychological comorbidity to pain also need to be considered. QST may prove useful for objective assessment of pair } \\
\text { mechanisms, but requires more validation }\end{array}$ \\
\hline Design & $\begin{array}{l}\text { Adequately powered studies, well-defined patient cohorts and randomisation are essential. However, without sham-controlled studies, it is not possible } \\
\text { to determine non-placebo effect sizes of treatment. }\end{array}$ \\
\hline
\end{tabular}

QST, Quantitative sensory testing; TPIAT, total pancreatectomy with islet autotransplantation.

Pain evolution has a significant impact on the outcomes from invasive treatment. Observational studies of surgical and endoscopic therapy have shown improved outcomes when performed during the early phase of $\mathrm{CP},{ }^{98}$ especially prior to the onset of narcotic dependence and central sensitisation. ${ }^{142683-8599-102}$ The previously mentioned ESCAPE trial may provide data on this factor.

Pain pattern is another important factor to consider. CP patients with constant pain pattern often have a worse quality of life, more lost work days, increased number of hospitalisations, higher pain intensity and more night pain. ${ }^{62} 103$ Constant pain was also associated with higher levels of exocrine insufficiency and malnutrition. ${ }^{104} 105$ Finally, constant pain is a predictor of failed surgical treatment for painful CP. ${ }^{106}$ On the other hand, intermittent pain associated with recurrent acute pancreatitis is a positive predictor in patients having TPIAT. $^{43}$ Correspondingly, TPIAT is more effective in the paediatric CP patients, ${ }^{107} 108$ which might be explained by an immature pain system that is less likely to undergo the irreversible neuroplastic changes observed in adult patients. The effect of pain pattern is supported by studies in patients with other painful neuropathic conditions, where a constant pain pattern was also associated with a worse outcome from treatment. $^{109}$

Opioid use is associated with more hospitalisations, ${ }^{105}$ and is a predictor of failure from surgical treatment. ${ }^{83}$ Opioids can interfere with pain processing, and in some instances, contribute to hyperalgesia. ${ }^{110}$ In an individual patient, it is difficult to determine whether opioids worsen the response to treatment. Patients with opioid dependence are generally those with more severe pain and lower quality of life, and as such are more likely to be refractory to treatment.

Subjective pain assessment is highly variable and the instruments are poorly validated. ${ }^{111}$ Yet, this is the primary indication for the treatment of patients with $\mathrm{CP}$ and the most important endpoint of trials. The 'IMMPACT guidelines' recommend that patient factors, study design, study site factors and outcome measurements are all used in pain evaluation, ${ }^{112} 113$ and patient-reported characteristics should also be used in assessing the response to invasive treatments. ${ }^{2} 111$ As most invasive treatment studies have used only simple pain assessment instruments, it is mandatory to use better validated and more comprehensive measures in future trials. ${ }^{103} 114115$

Objective pain assessment includes QST $^{11}$ and can be combined with subjective pain assessment, neurophysiological and imaging methods. ${ }^{19}$ Visceral QST has been used in the evaluation of many pain conditions ${ }^{11}$ but the invasiveness has limited its use in clinical practice. Visceral QST has also been used in CP to explore different pain mechanisms. ${ }^{19}$ A bedside solution that assesses somatic pain sensitivity as a proxy for the changes in the central nervous system caused by CP has recently been developed and validated. ${ }^{116} 117$ This has been shown to reflect disease severity and to predict the outcome of medical and surgical treatment for painful CP. ${ }^{66}$ 116-119 However, further studies, including normative reference data and additional validation in CP patients without pain, are required before this approach can be used in clinical practice.

\section{CONCLUSION}

Pain is the predominant and most incapacitating symptom of $\mathrm{CP}$, and current guidelines recommend treatment by a step-up approach comprising an initial pain medication, followed by interventions including endoscopy and surgery. However, as highlighted in this debate article, the conceptual basis for these interventions (ie, reducing pressure in pancreatic duct, removing ductal stones and resecting inflammatory masses to remove local nociceptive source) does not take into account the advances in our understanding of pain mechanisms, and in particular, the importance of neuropathy and neuroplastic changes in the central nervous system. Furthermore, there is a paucity of data from prospective, randomised and adequately controlled clinical trials as basis for the current interventional treatment recommendations. Although showing that interventions improve pain in $\mathrm{CP}$, most randomised trials compare different types of interventions or the timing of interventions, rather than questioning the indication for interventions to treat pain in CP, an assumption that may indeed be challenged, as described by the 'con-authors' in this debate. Furthermore, many trials do not take into account that $\mathrm{CP}$ is heterogeneous in many factors such as aetiology, stage, duration and pre-treatments, and thus different patients may require different treatment approaches, making a point for the personalisation of algorithms for the treatment of pain in CP. To make progress towards a better understanding of the benefits of invasive treatments in $\mathrm{CP}$, it is necessary to conduct studies with appropriate control arms wherever possible. 
Additionally, further trials should take a more comprehensive and validated approach to pain assessment, taking into account the many factors that influence pain and the efficacy of treatment, especially the development of central sensitisation. Future RCTs should involve all required disciplines such as pain specialists, pancreatologists, interventional endoscopists and pancreatic surgeons to ensure an appropriate design and a widespread acceptance of the results.

Overall, this debate shows that there is an urgent need for well-designed, prospective RCTs in this field of research. Gut hopes that this debate article has contributed to summarise the current evidence and the controversies in the treatment of pain in CP, and will foster future research.

Correction notice This article has been corrected since it published Online First. The contributors statement and second affiliation have been updated.

Contributors 'Con-authors' ordered according to their role in this part of the manuscript: AMD, SSO, LA-N, BM, VKS. 'Pro-authors' ordered according to their role in this part of the manuscript: MAK, SAWB, JEvH, HCVS, DKA, MLF, JAW, MJB, MAB , MGB for the Dutch Pancreatitis Study Group. Editorial author from Gut : TMG. AMD and MAK contributed equally

Funding The authors have not declared a specific grant for this research from any funding agency in the public, commercial or not-for-profit sectors.

Competing interests None declared.

Patient consent for publication Not required.

Provenance and peer review Not commissioned; internally peer reviewed.

Author note TMG is associate editor of Gut and was assigned the task to coordinate and moderate the debate and the manuscript's introductory and concluding remarks.

\section{(6) OPEN ACCESS}

Open access This is an open access article distributed in accordance with the Creative Commons Attribution Non Commercial (CC BY-NC 4.0) license, which permits others to distribute, remix, adapt, build upon this work non-commercially, and license their derivative works on different terms, provided the original work is properly cited, appropriate credit is given, any changes made indicated, and the use is non-commercial. See: http:// creativecommons.org/licenses/by-nc/4.0/.

(c) Author(s) (or their employer(s)) 2019. Re-use permitted under CC BY-NC. No commercial re-use. See rights and permissions. Published by BMJ.

\section{Check for updates}

To cite Drewes AM, Kempeneers MA, Andersen DK, et al. Gut 2019;68:1343-1351.

Received 20 March 2019

Revised 1 May 2019

Accepted 7 May 2019

Published Online First 25 May 2019
Gut 2019;68:1343-1351.

doi:10.1136/gutjnl-2019-318742

\section{REFERENCES}

1 Löhr JM, Dominguez-Munoz E, Rosendahl J, et al. United European Gastroenterology evidencebased guidelines for the diagnosis and therapy of chronic pancreatitis (HaPanEU). United European Gastroenterol J 2017;5:153-99.

2 Drewes AM, Bouwense SAW, Campbell CM, et al. Guidelines for the understanding and management of pain in chronic pancreatitis. Pancreatology 2017;17:720-31

3 Windsor JA, Reddy ND. Endoscopic vs. Surgical Interventions for Painful Chronic Pancreatitis: What is Needed for Future Clinical Trials. Clin Trans/ Gastroenterol 2017:8:e213.

4 Hoffmeister A, Mayerle J, Beglinger C, et al. English language version of the $S 3$-consensus guidelines on chronic pancreatitis: Definition, aetiology, diagnostic examinations, medical, endoscopic and surgical management of chronic pancreatitis. Z Gastroenterol 2015;53:1447-95.

5 Dumonceau J-M, Delhaye M, Tringali A, et al. Endoscopic treatment of chronic pancreatitis: European Society of Gastrointestinal Endoscopy (ESGE) Clinical Guideline. Endoscopy 2012:44:784-800

6 Frøkjær JB, Olesen SS, Drewes AM. Fibrosis, atrophy, and ductal pathology in chronic pancreatitis are associated with pancreatic function but independent of symptoms. Pancreas 2013:42:1182-7.

7 Wilcox CM, Yadav D, Ye T, et al. Chronic pancreatitis pain pattern and severity are independent of abdominal imaging findings. Clin Gastroenterol Hepatol 2015;13:552-60.

8 Jensen AR, Matzen P, Malchow-Møller A, et al. Pattern of pain, duct morphology, and pancreatic function in chronic pancreatitis. A comparative study. Scand J Gastroenterol 1984;19:334-8.

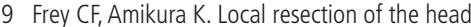
of the pancreas combined with longitudinal pancreaticojejunostomy in the management of patients with chronic pancreatitis. Ann Surg 1994:220:492-507.

10 Sinha A, Patel YA, Cruise M, et al. Predictors of Post-Operative Pain Relief in Patients with Chronic Pancreatitis Undergoing the Frey or Whipple Procedure. J Gastrointest Surg 2016;20:734-40.

11 Arendt-Nielsen L, Morlion B, Perrot S, et al. Assessment and manifestation of central sensitisation across different chronic pain conditions. Eur J Pain 2018;22:216-41.

12 Rösch T, Daniel S, Scholz M, et al. Endoscopic treatment of chronic pancreatitis: a multicenter study of 1000 patients with long-term follow-up. Endoscopy 2002;34:765-71.

13 Cahen DL, Gouma DJ, Nio Y, et al. Endoscopic versus surgical drainage of the pancreatic duct in chronic pancreatitis. N Engl J Med 2007;356:676-84.

14 Clarke B, Slivka A, Tomizawa Y, et al. Endoscopic therapy is effective for patients with chronic pancreatitis. Clin Gastroenterol Hepatol 2012;10:795-802.

15 Drewes AM, Krarup AL, Detlefsen S, et al. Pain in chronic pancreatitis: the role of neuropathic pain mechanisms. Gut 2008;57:1616-27.

16 Demir IE, Friess H, Ceyhan GO. Neural plasticity in pancreatitis and pancreatic cancer. Nat Rev Gastroenterol Hepatol 2015;12:649-59.

17 Woolf CJ. Central sensitization: implications for the diagnosis and treatment of pain. Pain 2011;152:S2-S15.

18 Woolf CJ, Salter MW. Neuronal plasticity: increasing the gain in pain. Science 2000;288:1765-8.

19 Olesen SS, Krauss T, Demir IE, et al. Towards a neurobiological understanding of pain in chronic pancreatitis: mechanisms and implications for treatment. Pain Rep 2017;2:e625.

20 Bouwense SA, Buscher HC, van Goor H, et al. Has central sensitization become independent of nociceptive input in chronic pancreatitis patients who fail thoracoscopic splanchnicectomy? Reg Anesth Pain Med 2011;36:531-6.

21 Backonja M, Wallace MS, Blonsky ER, et al. NGX4010, a high-concentration capsaicin patch, for the treatment of postherpetic neuralgia: a randomised, double-blind study. Lancet Neurol 2008;7:1106-12.

22 Vaso A, Adahan HM, Gjika A, et al. Peripheral nervous system origin of phantom limb pain. Pain 2014; 155:1384-91.

23 Meier T, Wasner G, Faust M, et al. Efficacy of lidocaine patch $5 \%$ in the treatment of focal peripheral neuropathic pain syndromes: a randomized, double-blind, placebo-controlled study. Pain 2003:106:151-8.

24 Arendt-Nielsen L. Pain sensitisation in osteoarthritis. Clin Exp Rheumatol;35 Suppl 1:68-74.

25 Colloca L, Ludman T, Bouhassira D, et al. Neuropathic pain. Nat Rev Dis Primers 2017;3:17002.

26 Cahen DL, Gouma DJ, Laramée P, et al. Long-term outcomes of endoscopic vs surgical drainage of the pancreatic duct in patients with chronic pancreatitis. Gastroenterology 2011;141:1690-5.

27 Chedid KJ, Chedid MK. The "tract" of history in the treatment of lumbar degenerative disc disease. Neurosurg Focus 2004;16:1-4.

28 Loeser JD. Other surgical interventions. Pain Pract 2006;6:58-62

29 Machado GC, Witzleb AJ, Fritsch C, et al. Patients with sciatica still experience pain and disability 5 years after surgery: A systematic review with meta-analysis of cohort studies. Eur J Pain 2016:20:1700-9.

30 Petersen KK, Simonsen O, Laursen MB, et al. Chronic postoperative pain after primary and revision total knee arthroplasty. Clin J Pain 2015;31:1-6.

31 Skou ST, Graven-Nielsen T, Rasmussen S, et al. Widespread sensitization in patients with chronic pain after revision total knee arthroplasty. Pain 2013:154:1588-94.

32 Drewes AM, Campbell CM, Ceyhan GO, et al. Pain in pancreatic ductal adenocarcinoma: A multidisciplinary, International guideline for optimized management. Pancreatology 2018;18:446-57.

33 Carvajal G, Dupoiron D, Seegers V, et al. Intrathecal drug delivery systems for refractory pancreatic cancer pain: Observational follow-up study over an 11-year period in a comprehensive cancer center. Anesth Analg 2018;126:2038-46.

34 Kapural L, Cywinski JB, Sparks DA. Spinal Cord Stimulation for Visceral Pain From Chronic Pancreatitis. Neuromodulation: Technology at the Neural Interface 2011;14:423-7.

35 Forsmark CE. Management of chronic pancreatitis. Gastroenterology 2013;144:1282-91.

36 Andersen DK, Frey CF. The evolution of the surgical treatment of chronic pancreatitis. Ann Surg 2010:251:18-32.

37 Strate T, Taherpour Z, Bloechle C, et al. Long-term follow-up of a randomized trial comparing the beger and frey procedures for patients suffering from chronic pancreatitis. Ann Surg 2005;241:591-8.

38 Keck T, Adam U, Makowiec F, et al. Short- and long-term results of duodenum preservation versus resection for the management of chronic pancreatitis: a prospective, randomized study. Surgery 2012;152(3 Suppl 1):S95-S102.

39 Bachmann K, Tomkoetter L, Kutup A, et al. Is the Whipple procedure harmful for long-term outcome in treatment of chronic pancreatitis? 15-years follow-up comparing the outcome after pylorus-preserving pancreatoduodenectomy and Frey procedure in chronic pancreatitis. Ann Surg 2013;258:815-21. 
40 Turner JA, Deyo RA, Loeser JD, et al. The importance of placebo effects in pain treatment and research. JAMA 1994;271:1609-14.

41 Wilcox CM. Tinkering with a tarnished technique: isn't it time to abandon celiac plexus blockade for the treatment of abdominal pain in chronic pancreatitis? Clin Gastroenterol Hepatol 2012;10:106-8.

42 Fusaroli P, Caletti G. Is there a role for celiac plexus block for chronic pancreatitis? Endosc Int Open 2015;03:E60-E62.

43 Moran RA, Klapheke R, John GK, et al. Prevalence and predictors of pain and opioid analgesic use following total pancreatectomy with islet autotransplantation for pancreatitis. Pancreatology 2017:17:732-7.

44 Capurso G, Cocomello L, Benedetto U, et al. Meta-analysis: the placebo rate of abdominal pain remission in clinical trials of chronic pancreatitis. Pancreas 2012:41:1125-31.

45 Hróbjartsson A, Gøtzsche PC. Placebo interventions for all clinical conditions. Cochrane Database Syst Rev 2010;1:CD003974.

46 Enck $P$, Chae Y, Elsenbruch S. Novel designs and paradigms to study the placebo response in gastroenterology. Curr Opin Pharmacol 2017;37:72-9.

47 Beard DJ, Rees JL, Cook JA, et al. Arthroscopic subacromial decompression for subacromial shoulder pain (CSAW): a multicentre, pragmatic, parallel group, placebo-controlled, three-group, randomised surgical trial. Lancet 2018;391:329-38

48 Al-Lamee R, Thompson D, Dehbi HM, et al. Percutaneous coronary intervention in stable angina (ORBITA): a double-blind, randomised controlled trial. Lancet 2018:391:31-40.

49 Firanescu CE, de Vries J, Lodder $\mathrm{P}$, et al. Vertebroplasty versus sham procedure for painful acute osteoporotic vertebral compression fractures (VERTOS IV): randomised sham controlled clinical trial. BMJ 2018;361:k1551.

50 Swank DJ, Swank-Bordewijk SCG, Hop WCJ, et al. Laparoscopic adhesiolysis in patients with chronic abdominal pain: a blinded randomised controlled multi-centre trial. The Lancet 2003;361:1247-51.

51 Cullen KA, Hall MJ, Golosinskiy A. Ambulatory surgery in the United States, 2006. Natl Health Stat Report 2009:11:1-25.

52 Sihvonen R, Paavola M, Malmivaara A, et al. Arthroscopic partial meniscectomy versus sham surgery for a degenerative meniscal tear. $N$ Eng/ $J$ Med 2013:369:2515-24.

53 Brophy R. Arthroscopic partial meniscectomy was not better than sham surgery for medial meniscal tear. $J$ Bone Joint Surg Am 2014;96:1396.

54 Wartolowska K, Judge A, Hopewell S, et al. Use of placebo controls in the evaluation of surgery: systematic review. BMJ 2014;348:g3253.

55 Jonas WB, Crawford C, Colloca L, et al. To what extent are surgery and invasive procedures effective beyond a placebo response? A systematic review with meta-analysis of randomised, sham controlled trials. BMJ Open 2015;5:e009655.

56 Gu AP, Gu CN, Ahmed AT, et al. Sham surgical procedures for pain intervention result in significant improvements in pain: systematic review and metaanalysis. J Clin Epidemio/ 2017;83:18-23.

57 Cotton PB, Durkalski V, Romagnuolo J, et al. Effect of endoscopic sphincterotomy for suspected sphincter of Oddi dysfunction on pain-related disability following cholecystectomy: the EPISOD randomized clinical trial. JAMA 2014;311:2101.

58 Cotton PB. Why did the sham-treated EPISOD study subjects do so well? Important lessons for research and practice. Gastrointest Endosc 2018 https://linkinghub.elsevier.com/retrieve/pii/ S001651071833267X (cited 26 Feb 2019).
59 Cooper MA, Datta TS, Makary MA. Laparoscopic frey procedure for chronic pancreatitis. Surg Laparosc Endosc Percutan Tech 2014;24:e16-e20.

60 Jadad AR, Browman GP. The WHO analgesic ladder for cancer pain management. Stepping up the quality of its evaluation. JAMA 1995;274:1870-3.

61 Díte P, Ruzicka M, Zboril V, et al. A prospective, randomized trial comparing endoscopic and surgical therapy for chronic pancreatitis. Endoscopy 2003:35:553-8.

62 Mullady DK, Yadav D, Amann ST, et al. Type of pain, pain-associated complications, quality of life, disability and resource utilisation in chronic pancreatitis: a prospective cohort study. Gut 2011:60:77-84

63 Nusrat S, Yadav D, Bielefeldt K. Pain and opioid use in chronic pancreatitis. Pancreas 2012;41:264-70.

64 Lee M, Silverman SM, Hansen $H$, et al. A comprehensive review of opioid-induced hyperalgesia. Pain Physician 2011;14:145-61.

65 O'Brien T, Christrup LL, Drewes AM, et al. European Pain Federation position paper on appropriate opioid use in chronic pain management. Eur J Pain 2017;21:3-19.

66 Bouwense SA, Olesen SS, Drewes AM, et al. Is altered central pain processing related to disease stage in chronic pancreatitis patients with pain? An exploratory study. PLoS One 2013;8:e55460.

67 Olesen SS, Bouwense SA, Wilder-Smith OH, et al. Pregabalin reduces pain in patients with chronic pancreatitis in a randomized, controlled trial. Gastroenterology 2011;141:536-43.

68 Ammann RW, Muench R, Otto R, et al. Evolution and regression of pancreatic calcification in chronic pancreatitis. A prospective long-term study of 107 patients. Gastroenterology 1988;95:1018-28.

69 Maydeo A, Soehendra N, Reddy N, et al. Endotherapy for chronic pancreatitis with intracanalar stones. Endoscopy 2007:39:653-8.

70 Dumonceau J-M, Delhaye M, Tringali A, et al. Endoscopic treatment of chronic pancreatitis: European Society of Gastrointestinal Endoscopy (ESGE) Guideline - Updated August 2018. Endoscopy 2019:51:179-93.

71 Tadenuma H, Ishihara T, Yamaguchi T, et al. Long-term results of extracorporeal shockwave lithotripsy and endoscopic therapy for pancreatic stones. Clinical Gastroenterology and Hepatology 2005;3:1128-35.

72 Dumonceau JM, Costamagna G, Tringali A, et al. Treatment for painful calcified chronic pancreatitis: extracorporeal shock wave lithotripsy versus endoscopic treatment: a randomised controlled trial. Gut 2007:56:545-52.

73 Partington PF, Rochelle RE. Modified Puestow procedure for retrograde drainage of the pancreatic duct. Ann Surg 1960;152:1037-43.

74 Beger HG, Krautzberger W, Bittner R, et al. Duodenum-preserving resection of the head of the pancreas in patients with severe chronic pancreatitis. Surgery 1985;97:467-73.

75 Gloor B, Friess H, Uhl W, et al. A modified technique of the beger and frey procedure in patients with chronic pancreatitis. Dig Surg 2001;18:21-5.

76 Frey CF, Smith GJ. Description and rationale of a new operation for chronic pancreatitis. Pancreas 1987;2:701-7

77 van der Gaag NA, van Gulik TM, Busch OR, et al. Functional and medical outcomes after tailored surgery for pain due to chronic pancreatitis. Ann Surg 2012:255:763-70

78 Diener MK, Rahbari NN, Fischer L, et al. Duodenumpreserving pancreatic head resection versus pancreatoduodenectomy for surgical treatment of chronic pancreatitis: a systematic review and metaanalysis. Ann Surg 2008;247:950-61.

79 Strate T, Bachmann K, Busch P, et al. Resection vs drainage in treatment of chronic pancreatitis: long term results of a randomized trial. Gastroenterology 2008;134:1406-11.

80 Diener MK, Hüttner FJ, Kieser M, et al. Partial pancreatoduodenectomy versus duodenumpreserving pancreatic head resection in chronic pancreatitis: the multicentre, randomised, controlled, double-blind ChroPac trial. Lancet 2017;390:1027-37.

81 Najarian JS, Sutherland DE, Matas AJ, et al. Human islet transplantation: a preliminary report. Transplant Proc 1977:9:233-6.

82 Bellin MD, Beilman GJ, Sutherland DE, et al. How Durable Is Total Pancreatectomy and Intraportal Islet Cell Transplantation for Treatment of Chronic Pancreatitis? J Am Coll Surg 2019;228:329-39.

83 Ahmed Ali U, Nieuwenhuijs VB, van Eijck CH, et al. Clinical outcome in relation to timing of surgery in chronic pancreatitis: a nomogram to predict pain relief. Arch Surg 2012;147:925-32.

84 Ke N, Jia D, Huang W, et al. Earlier surgery improves outcomes from painful chronic pancreatitis. Medicine 2018:97:e0651.

85 Yang CJ, Bliss LA, Schapira EF, et al. Systematic review of early surgery for chronic pancreatitis: impact on pain, pancreatic function, and re-intervention. J Gastrointest Surg 2014:18:1863-9.

86 Bouwense SA, Ahmed Ali U, ten Broek RP, et al. Altered central pain processing after pancreatic surgery for chronic pancreatitis. Br J Surg 2013;100:1797-804.

87 Bouwense SA, de Vries M, Schreuder LT, et al. Systematic mechanism-orientated approach to chronic pancreatitis pain. World J Gastroenterol 2015;21:47-59.

88 Ahmed Ali U, Issa Y, Bruno MJ, et al. Early surgery versus optimal current step-up practice for chronic pancreatitis (ESCAPE): design and rationale of a randomized trial. BMC Gastroenterol 2013;13:49.

89 Bloechle C, Izbicki JR, Knoefel WT, et al. Quality of life in chronic pancreatitis-results after duodenumpreserving resection of the head of the pancreas. Pancreas 1995:11:77-85.

90 Izbicki JR, Bloechle C, Broering DC, et al. Extended drainage versus resection in surgery for chronic pancreatitis: a prospective randomized trial comparing the longitudinal pancreaticojejunostomy combined with local pancreatic head excision with the pylorus-preserving pancreatoduodenectomy. Ann Surg 1998;228:771-9.

91 Brim RL, Miller FG. The potential benefit of the placebo effect in sham-controlled trials: implications for risk-benefit assessments and informed consent. J Med Ethics 2013:39:703-7.

92 Miller FG, Kaptchuk TJ. Sham procedures and the ethics of clinical trials. J $R$ Soc Med 2004;97:576-8.

93 Chinnakotla S, Beilman GJ, Dunn TB, et al. Factors predicting outcomes after a total pancreatectomy and islet autotransplantation lessons learned from over 500 cases. Ann Surg 2015:262:610-22.

94 Sinha A, Singh VK, Cruise M, et al. Abdominal CT predictors of fibrosis in patients with chronic pancreatitis undergoing surgery. Eur Radiol 2015;25:1339-46.

95 Dunderdale J, McAuliffe JC, McNeal SF, et al. Should pancreatectomy with islet cell autotransplantation in patients with chronic alcoholic pancreatitis be abandoned? J Am Coll Surg 2013;216:591-6.

96 Morgan KA, Lancaster WP, Owczarski SM, et al. Patient selection for total pancreatectomy with islet autotransplantation in the surgical management of chronic pancreatitis. J Am Coll Surg 2018:226:446-51.

97 Eisenach JC, Brennan TJ. Pain after surgery. Pain 2018:159:1010-1.

98 Bordaçahar B, Couvelard A, Vullierme MP, et al. Predicting the efficacy of surgery for pain relief in patients with alcoholic chronic pancreatitis. Surgery 2018;164:1064-70. 
99 Nealon WH, Thompson JC. Progressive loss of pancreatic function in chronic pancreatitis is delayed by main pancreatic duct decompression. A longitudinal prospective analysis of the modified puestow procedure. Ann Surg 1993;217:458-68.

100 Dumonceau JM, Devière J, Le Moine 0, et al. Endoscopic pancreatic drainage in chronic pancreatitis associated with ductal stones: long-term results. Gastrointest Endosc 1996;43:547-55.

101 Delhaye M, Arvanitakis M, Verset G, et al. Long-term clinical outcome after endoscopic pancreatic ductal drainage for patients with painful chronic pancreatitis. Clin Gastroenterol Hepatol 2004;2:1096-106.

102 Bellin MD, Prokhoda P, Hodges JS, et al. Age and disease duration impact outcomes of total pancreatectomy and islet autotransplant for PRSS1 Hereditary pancreatitis. Pancreas 2018;47:1-70.

103 Teo K, Johnson MH, Drewes AM, et al. A comprehensive pain assessment tool (COMPAT) for chronic pancreatitis: Development, face validation and pilot evaluation. Pancreatology 2017; 17:706-19.

104 Olesen SS, Frandsen LK, Poulsen JL, et al. The prevalence of underweight is increased in chronic pancreatitis outpatients and associates with reduced life quality. Nutrition 2017;43-44:1-7.
105 Olesen SS, Poulsen JL, Broberg MC, et al. Opioid treatment and hypoalbuminemia are associated with increased hospitalisation rates in chronic pancreatitis outpatients. Pancreatology 2016;16:807-13.

106 Negi S, Singh A, Chaudhary A. Pain relief after Frey's procedure for chronic pancreatitis. Br J Surg 2010;97:1087-95.

107 Walco GA, Dworkin RH, Krane EJ, et al. Neuropathic pain in children: Special considerations. Mayo Clin Proc 2010;85:S33-S41.

108 Chinnakotla S, Bellin MD, Schwarzenberg SJ, et al. Total Pancreatectomy and Islet Autotransplantation in Children for Chronic Pancreatitis. Ann Surg 2014;260:56-64.

109 Martini CH, Yassen A, Krebs-Brown A, et al. A novel approach to identify responder subgroups and predictors of response to low- and high-dose capsaicin patches in postherpetic neuralgia. Eur J Pain 2013;17:n/a.

110 Szigethy E, Knisely M, Drossman D. Opioid misuse in gastroenterology and non-opioid management of abdominal pain. Nat Rev Gastroenterol Hepatol 2018;15:168-80.

111 Teo K, Johnson MH, Truter S, et al. Pain assessment in chronic pancreatitis: A comparative review of methods. Pancreatology 2016;16:931-9.

112 Dworkin RH, Turk DC, Wyrwich KW, et al. Interpreting the clinical importance of treatment outcomes in chronic pain clinical trials: IMMPACT recommendations. J Pain 2008;9:105-21.

113 Dworkin RH, Turk DC, Peirce-Sandner S, et al. Considerations for improving assay sensitivity in chronic pain clinical trials: IMMPACT recommendations. Pain 2012;153:1148-58.

114 Olesen SS, Juel J, Nielsen AK, et al. Pain severity reduces life quality in chronic pancreatitis: Implications for design of future outcome trials. Pancreatology 2014;14:497-502.

115 Seicean A, Grigorescu M, Tanțău M, et al. Pain in chronic pancreatitis: assessment and relief through treatment. Rom J Gastroenterol 2004;13:9-15.

116 Kuhlmann L, Olesen SS, Olesen AE, et al. Mechanismbased pain management in chronic pancreatitis - is it time for a paradigm shift? Expert Rev Clin Pharmacol 2019;12:249-58.

117 Kuhlmann L, Olesen S, Grønlund D, et al. Clinical pain phenotype associates with sensory testing results in chronic pancreatitis. Clin J Pain 2019.

118 Olesen SS, van Goor H, Bouwense SA, et al. Reliability of static and dynamic quantitative sensory testing in patients with painful chronic pancreatitis. Reg Anesth Pain Med 2012;37:530-6.

119 Olesen SS, Graversen C, Bouwense SA, et al. Quantitative sensory testing predicts pregabalin efficacy in painful chronic pancreatitis. PLoS One 2013;8:e57963. 